\title{
Experimental Study on the Cutting Propagation of a Precious Medicinal Plant Grow in the Wild named Inula japonica Thunb
}

\author{
Zhihui Yu \\ Jilin Agricultural Science and Technology University, Jilin, Jilin Province, China
}

Keywords: Inula japonica Thunb.; cutting; medium; hormones.

\begin{abstract}
Inula japonica Thunb. is a precious flowering plant grow in the wild; it can be used as medicine. In order to find out the best cutting procedure, comparative experiments are carried out from three aspects: type of medium, time of cutting and hormone treatment. The results show that the best cutting medium of Inula is the combination of turfy soil and perlite (3:1); June is the best month for cutting; the species and concentrations of hormones can significantly affect the rooting of Inula cutting slips. When the concentration of NAA is $100 \mathrm{mg} / \mathrm{L}$, the rooting rate is the highest at $84.7 \%$.
\end{abstract}

\section{Introduction}

Inula japonica Thunb. (hereinafter referred to as Inula or Inula flowers), also known as the golden Buddha flower, belongs to Inula, Compositae family. It is a kind of perennial herb grow in the wild. Inula flowers have high ornamental value. Its florescence is from July to October; the fruiting season is from August to November. Inula flowers can be found in northeast China and north China; they tend to grow along hillside roads and fields, in wetlands at the edge of forests, and in grasslands in valleys at about $200-1,000$ m altitude. The plant can tolerant cold and barren soil, but cannot resist drought. The flowers are orange and yellow, with flower season from June to September. It can be used in flower borders and scattered cut-flower materials. [1] Both at home and abroad, most scholars tend to study cultivated Inula varieties and their medicinal values; they especially focus on studying Inula plants' compositions, structures and chemical compositions, and exploring how to extract formula granule and endogenous hormones. The functional resistance of human body is also a hot research topic. Studies have shown that, [2-7] the main chemical components of Inula flowers are sterols, flavonoids, sesquiterpenes, terpenes and volatile oils. Sesquiterpene lactone compounds are the characteristic effective component of Inula japonica Thunb; they have obvious pharmacological effects such as anti-tumor, anti-inflammation, anti-ulcer, diuresis and anti-cough. But at present, its application in landscape construction is still in blank [8] [9]. At present, most Inula flowers used in medicine grow in wild; they have not been planted in a large scale. In terms of reproduction, in vitro seedling propagation and tissue culture propagation are the mainstream. [10] [11] However, studies on the cutting propagation technique, a method which can rapidly form seedlings and effectively maintain the excellent ornamental characteristics, has not been reported. [12] [13] In this paper, the growth conditions of Inula flowers were studied under the conditions of different media, different cutting times and different hormone treatments. The paper provides an effective technical basis for the large scale production and mass reproduction of this precious wild ornamental plant.

\section{Research Materials and Methods}

\subsection{Research materials}

The experimental materials were grown Inula plants which were collected from the experimental base of the Landscape Architecture Department of Beihua University in Jilin in mid-may 2016. These plants were embedded in the No. 1 Greenhouse in the garden spot of Jilin Agricultural Science and Technology University. After seedlings grew up and became mature, they were used in the 
experiment.

\subsection{Research method}

Processing of cutting. Healthy, disease-free twigs of Inula plants were selected as cutting slips. The length of cutting slips was $10-15 \mathrm{~cm}$ (2-3 leaflets are kept); the cut should be smooth. Leaves near the roots were removed; upper leaves were trimmed properly. The cutting slips were tied into bundles and soaked in clear water.

Treatment of the medium. All media in the test were newly purchased. After fully mixing required media according to the set volume ratios, media were treated with $0.05 \%$ concentration $\mathrm{KMnO} 4$ solution, and rinsed by water after 24 hours.

\subsection{Experimental design}

The method of repeated single factor was adopted. 50 cutting slips composed one group and repeated for three times. The cutting depth was 4-6 cm; row spacing was $10 \mathrm{~cm} \times 10 \mathrm{~cm}$. Leaves should be moist during the whole process. Rooting indexes such as rooting rate, average root length, root diameter and number of roots were measured after 30 days.

Cutting medium test. In late June of 2016, the comparative test on cutting medium was carried out. Raw materials are turfy soil, perlite and sand. Raw materials are mixed according to different ratios. This test includes four processing methods: normal nutrition soil, sand, turfy soil: perlite: sand (1:1:1) and turfy soil: perlite (3:1), and common nutritional soil as the control group.

Hormone treatment test. In early September of 2016, the comparative hormone treatment test was carried out. The cutting medium was the same, namely turfy soil : perlite (3:1) . The hormone treatment methods were IAA, IBA and NAA, with clear water as the control group. The concentrations were $100 \mathrm{mg} / \mathrm{L}, 200 \mathrm{mg} / \mathrm{L}$ and 300mg/L respectively. After processing, the bottom of cutting slips was soaked in different solutions at the depth of $1 \mathrm{~cm}$. The cutting process was carried out after 1 hour.

Time of cutting. Cutting experiments were conducted in the first half of June, July and August respectively. The cutting medium was the same, namely turfy soil: perlite (3:1).

\subsection{Data analysis}

Microsoft Excel 2016 was used for data statistics; SPSS2.0 was used for statistical analysis.

\section{Results and Analysis}

\subsection{Influence of media on the rooting of Inula cutting slips}

The suitable media were selected. The experiment indicated (see table 1) that different media can lead to different results. The rooting rate of Inula (87\%) in medium 3 was significantly higher than that of cutting slips planted in the other three media. The rooting rate of plants in medium 1 was the lowest, $72 \%$, which was significantly different from the rooting rate of cutting slips in medium 3 . The rooting rates of plants in medium 2 and medium 4 were relatively low, respectively $80 \%$ and $76 \%$. The results showed that Inula flower was suitable to grow in the media of turfy soil and perlite (3:1).

Table1. Effects of different media on the rooting of Inula cutting slips

\begin{tabular}{|c|c|c|c|c|c|}
\hline No. & Medium & $\begin{array}{c}\text { Rooting rate } \\
(\%)\end{array}$ & $\begin{array}{l}\text { Average root } \\
\text { length }(\mathrm{cm})\end{array}$ & $\begin{array}{r}\text { Average stem } \\
\text { diameter }(\mathrm{mm})\end{array}$ & $\begin{array}{l}\text { Average number of } \\
\text { roots }\end{array}$ \\
\hline 1 & sand & $72.5 \mathrm{~d} \mathrm{C}$ & $1.62 \mathrm{~d} \mathrm{C}$ & 0.57 c C & 6.75 с B \\
\hline 2 & $\begin{array}{l}\text { turfy soil+perlite+sand } \\
(1: 1: 1)\end{array}$ & 80.5 b B & $2.33 \mathrm{~b} \mathrm{~B}$ & $0.71 \mathrm{~b} \mathrm{~B}$ & 7.92 b B \\
\hline 3 & turfy soil: perlite (3:1) & 87.3 a A & 3.02 a A & 0.81 a $\mathrm{A}$ & 11.25 a A \\
\hline 4 & common nutritional soil & 76.0 с BC & $1.81 \mathrm{c} \mathrm{C}$ & $0.70 \mathrm{~b} \mathrm{~B}$ & 7.04 с B \\
\hline
\end{tabular}

Note: different lowercase letters in the table indicate significant differences between treatments $(\mathrm{P}<0.05)$, while different uppercase letters indicate extremely significant differences between 
treatments $(\mathrm{P}<0.01)$.

\subsection{Effects of hormone treatment on the rooting of Inula cutting slips}

The effects of different hormone treatments of IAA, IBA and NAA on the rooting of Inula cutting slips were shown in table 2 . The rooting rates, number of roots, average root length and average stem diameter were significantly affected by different concentrations of IBA and NAA. However, the rooting of Inula flower in IAA treatment group was not significantly different from the control group. There were no significant differences in rooting rates among different concentrations of the same hormone. There were no significant differences in root length, stem diameter and the number of roots, indicating that the promoting effects of hormone were not obvious. When NAA concentration was $100 \mathrm{mg} / \mathrm{L}$, the rooting rate, number of root, average root length and average stem diameter all reached the maximum, namely $84.7 \%, 13.42,2.68 \mathrm{~cm}$ and $0.87 \mathrm{~cm}$ respectively. At the same time, it can be seen from table 2, with the increasing concentration of NAA root powder, all indexes decreased. It shows that if the concentrations of NAA root powder exceed a certain range, the rooting of Inula cutting slips will be inhibited.

Table 2. Effects of different hormones and different concentrations on rooting rates

\begin{tabular}{|c|c|c|c|c|c|c|}
\hline No. & hormones & $\begin{array}{l}\text { Concentra- } \\
\text { tions } \\
(\mathrm{mg} / \mathrm{L})\end{array}$ & $\mathrm{CC}$ & $\begin{array}{l}\text { Average root } \\
\text { length }(\mathrm{cm})\end{array}$ & $\begin{array}{r}\text { Average stem } \\
\text { diameter (mm) }\end{array}$ & $\begin{array}{c}\text { Average number } \\
\text { of roots }\end{array}$ \\
\hline $1(\mathrm{~A})$ & & 100 & $69.4 \mathrm{~d} D$ & $1.62 \mathrm{~d} \mathrm{C}$ & 0.60 de $\mathrm{DE}$ & 7.98 fg DE \\
\hline 2(B) & IAA & 200 & $63.5 \mathrm{f} \mathrm{F}$ & 1.52 e D & 0.59 de $\mathrm{E}$ & 7.83 gh DE \\
\hline $3(\mathrm{C})$ & & 300 & 58.3 g G & $1.15 \mathrm{f} \mathrm{E}$ & $0.48 \mathrm{f} \mathrm{F}$ & 6.76 i F \\
\hline 4(D) & & 100 & 70.5 с CD & $1.62 \mathrm{~d} C$ & 0.68 bc BCD & 10.25 d C \\
\hline $5(\mathrm{E})$ & IBA & 200 & 67.2 e $E$ & $1.67 \mathrm{~cd} C$ & $0.71 \mathrm{~b} B$ & 9.64 e C \\
\hline $6(\mathrm{~F})$ & & 300 & $64.3 \mathrm{f} \mathrm{F}$ & 1.54 e D & $0.62 \mathrm{~cd} C D E$ & $8.37 \mathrm{f} \mathrm{D}$ \\
\hline $7(\mathrm{G})$ & & 100 & 84.7 aA & 2.68 a $\mathrm{A}$ & 0.87 a $\mathrm{A}$ & 13.42 a A \\
\hline $8(\mathrm{H})$ & NAA & 200 & $76.0 \mathrm{bB}$ & 1.69 с C & 0.69 b BC & 11.75 с B \\
\hline $9(\mathrm{I})$ & & 300 & 71.4 с C & 2.15 b B & 0.73 b B & 12.37 b B \\
\hline $\mathrm{CK}(\mathrm{J})$ & Clear water & 1 & $63.4 \mathrm{f} \mathrm{F}$ & 1.51 e D & 0.54 ef EF & 7.41 h EF \\
\hline
\end{tabular}

Note: different lowercase letters in the table indicate significant differences between treatments $(\mathrm{P}<0.05)$, while different uppercase letters indicate extremely significant differences between treatments $(\mathrm{P}<0.01)$.

\subsection{Influences of time of cutting on the rooting of Inula cutting slips}

Suitable cutting moments were selected in this paper. The results of experiments (see table 3) showed that the rooting rates of Inula cut in June was the highest, followed by plants cut in July. The rooting rate was $82.7 \%$ in June, significantly higher than that of July and August. In July and August, except the significant difference in average stem diameter, the differences of other indexes were not significant.

Table 3. The effects of different months on the rooting of Inula cutting slips

\begin{tabular}{cccccc}
\hline No. & month & $\begin{array}{c}\text { Rooting rate } \\
(\%)\end{array}$ & $\begin{array}{c}\text { Average root } \\
\text { length }(\mathrm{cm})\end{array}$ & $\begin{array}{c}\text { Average stem } \\
\text { diameter }(\mathrm{cm})\end{array}$ & $\begin{array}{c}\text { Average number } \\
\text { of roots }\end{array}$ \\
\hline 1 & June & $82.7 \mathrm{a}$ & $2.35 \mathrm{a}$ & $0.57 \mathrm{a}$ & $8.42 \mathrm{a}$ \\
2 & July & $45.3 \mathrm{~b}$ & $1.06 \mathrm{~b}$ & $0.12 \mathrm{~b}$ & $1.28 \mathrm{~b}$ \\
3 & August & $40.2 \mathrm{~b}$ & $0.89 \mathrm{~b}$ & $0.09 \mathrm{c}$ & $0.75 \mathrm{~b}$ \\
\hline
\end{tabular}

Note: different lowercase letters in the table indicate significant differences between treatments $(\mathrm{P}<0.5)$ 


\section{Conclusions}

(1) The best cutting medium of Inula is the combination of turfy soil and perlite (3:1).

(2) In the contrast experiment of hormones, the results showed that IBA and NAA rooting power had obvious promoting effects on the rooting of Inula cutting slips; the difference between IAA treatment and the control group was not obvious. When the concentration of NAA is $100 \mathrm{mg} / \mathrm{L}$, the rooting rate is the highest at $84.7 \%$. The comprehensive effects of the three hormones on rooting rate were all $100 \mathrm{mg} / \mathrm{L}>200 \mathrm{mg} / \mathrm{L}>300 \mathrm{mg} / \mathrm{L}$.

(3) In the selected moths of June, July and August, the most suitable time for cutting and rooting is June.

During the World Horticultural Exposition in Beijing, as a kind of imported wild flowers, Inula showed good ornamental effects in roadside green space and gardens. Through the author's observation and reproduction test in Jilin in recent years, it has been proved that Inula japonica Thunb. has the potential of popularizing. With good qualities, the flower can adapt to economic and extensive management methods. In the future, the application potential of Inula flowers in the greening of saline-alkali soils, hospitals, factories and mines should be further explored. It is believed that in the future, Inula flowers will have broad application prospect in horticulture.

\section{Acknowledgements}

Fund Project: This paper is supported by Foundation for Science and Technology Projects of the Thirteenth Five-Year Plan of Jilin Provincial Department of Education; it is also supported by Foundation for Key Discipline Projects of Jilin Agricultural Science and Technology University.

\section{References}

[1] Q. Si, X. Tu, et al., Investigation on the growth characteristics of Inula japonica Thunb and accompanying plants in different areas of Enshi Prefecture, J. Journal of Hubei Institute for Nationalities. 33 (2016) 49-52.

[2] X.R. Cheng, Study on the Chemical Compositions and Biological Activities of Four Species of Inula L., Shanghai Jiao Tong University, 2012.

[3] J.J. Tan, Discovery and Biological Activities of Novel Sesquiterpenes in Four Medicinal Plants of Inula L., Shanghai Jiao Tong University, 2011.

[4] J.H. Wang, Y.P. Hou, S.Q. Cai, et al., Experimental Study on the Anti-cough and Expectorant Effects of Inulicin, Collected Papers of International Traditional Chinese medicine Expo, China Review Academic Publishers, Beijing, 2003.

[5] Y.Z. Chen, J.K. Wen, M. Han, etc., Effects of 1-o-Acetylbritannilactone on cyclo-oxygenase-2 and intercellular adhesion molecule-1 expression in human vascular endothelia cells, J. Chinese Journal of Arteriosclerosis. 13 (2005)129-132.

[6] T. Zhang, G.H. Du, R.Y. Chen, A study on the bioactivity of sesquitterpenoids in Inula L. plants, J. Chinese Pharmaceutical Journal. 24 (2010) 1889-1894.

[7] L.M. Ma, Z. Liu, Y.M. Shang, et. al., Simultaneous determination of inulicin and deacetylinulicin in Inulae flos by HPLC, J. China Pharmacy. 27(2016) 369-371.

[8] A.N. He, et al., Comparison study on in vitro and in vivo antioxidant activities of Inula nervosa Wall. extracts from different parts, J. Chinese Pharmacological Bulletin. 1 (2016) 79-83.

[9] F.C. Chen, et al., Analysis on morphological characteristics, photosynthetic characteristics and chemical constituents of Inua lineariifolia from different populations, J. China Journal of Chinese Materia Medica. 22 (2015) 4389-4394.

[10] H.J. Zhou, Effects of different culture media and hormone concentration ratios on callus 
induction of Inula britannica, J. Jiangsu Agricultural Sciences. 2 (2010) 60-61.

[11] P.G. Cai, Application prospect of Inula flower in gardens, J. Xiandai Horticulture. 10 (2015)17-18.

[12] H.J. Zhou, Effects of TDZ on callus induction of Inula britannica, J. Hubei Agricultural Sciences. 4 (2010) 28-31.

[13] H.J. Zhou, Effects of CPPU at different concentrations on callus induction of Inula britannica, J. Hubei Agricultural Sciences. 3 (2012) 68-71. 